\title{
Implementasi Metode Jet Tempur Dalam Meningkatkan Bimbingan Baca Tulis Al Qur'an Di MTs Negeri 1 Kota Kediri
}

\author{
Mu'min Ali Murtado, ${ }^{1}$ Miftahudin ${ }^{2}$ \\ ${ }^{1}$ Pascasarjana Institut Agama Islam Tribakti Kediri, 2Institut Agama Islam Tribakti Kediri \\ 1mukminali234@gmail.com,2pakliek68@gmail.com
}

\begin{abstract}
The implementation of Jet Tempur Method can improve Al Qur'an reading guidance at Lirboyo Islamic Boarding School. These preliminary data form the basis of this research in First Middle School Of Islamic State 1 Kediri City. This research uses a descriptive qualitative approach by exploring data in depth according to the focus of the study. Data collection by observation, interview and documentation. After the data is collected and analyzed qualitatively, the data is processed by data reduction, data presentation and drawing conclusions. The results showed that (1) ustadaz at First Middle School Of Islamic State 1 Kediri had implemented Al Qur'an reading and writing guidance, with the jet fighter method well starting the planning, implementation and follow-up stages of the implementation of the fighter jet method which had given a good impact on students, (2) the results of the learning of reading and reading guidance of the Qur'an can be known through daily demonstrations by asking students to face their teacher and then evaluating and formative exams, final semester exams.
\end{abstract}

Keywords: The Jet Tempur Method, the Guidance on Writing the Qur'an

\begin{abstract}
Abstrak
Perarapan Metode Jet Tempur dapat meningkatkan bimbingan baca tulis $\mathrm{Al}$ Qur'an di Pondok Pesantern Lirboyo. Data awal tersebut, menjadi dasar penelitian ini di Madrasah Tsanawaiyah Negeri (MtsN) 1 Kota Kediri. Peneltian ini, menggunakan pendekatan kualitatif diskriptif dengan menggali data-data secara mendalam sesuai fokus penelitian. Pengumpulan data dengan cara observasi, wawancara dan dokumentasi. Setelah data terkumpul dan dianalisis secara kualitatif, maka data diolah dengan cara reduksi data, penyajian data dan penarikan kesimpulan. Hasil penelitian menunjukan bahwa (1) ustadaz di MTs Negeri 1 Kota Kediri sudah melaksanaka pembelajaran bimbingan baca tulis $\mathrm{Al}$ Qur,an dengan metode jet tempur dengan baik mulai tahap perencanaan, pelaksanaan dan tindak lanjut pelaksanaan metode jet tempur yang dilaksanakan sudah memberikan dampak yang baik terhadap peserta didik, (2) hasil pembelajaran bimbingan baca tulis Al Qur'an dapat di ketahu melalu demostrasi tiap harinya dengan meyuruh siswa meju menghadap ustadaznya kemudian selanjutnya evaluasi dan ujian pormatif, ujian akhir semester.
\end{abstract}


Kata Kunci: Metode Jet Tempur, Bimbingan Baca Tulis Al Qur'an

\section{Pendahuluan}

Al Qur'an adalah mukjizat yang diturunkan kepada Nabi Muhammad SAW, melalui perantaraan Malaikat Jibril. Sebagai mukjizat, membaca $\mathrm{Al}$ Qur'an dapat dijadikan petunjuk dalam hidup dan yang membacanya saja sebagai ibadah. ${ }^{1}$ Akan tetapi, di saat bersamaan pula, membaca Al Qur'an harus diimbangi dengan cara membaca dengan baik dan benar (tajwid).

Tujuan Allah menurunkan Al Qur'an adalah sebagai hidayah bagi manusia di dalam mengarungi hidupan di dunia secara baik, dan merupakan rahmat bagi seluruh alam semesta, serta sebagai petunjuk di antara yang hak dan yang batil, juga sebagai penjelas terhadap segala sesuatu, akhlak, moralitas, dan etika-etika yang patut dipraktikan manusia dalam kehidupan mereka. ${ }^{2}$ Dengan mempertimbangkan hal tersebut dan seiring dengan kemajuan zaman, tantangan orang tua semakin berat dalam mendidik anak-anaknya. Karena orang tua dituntut untuk bisa mendidik anakanaknya dengan berbagai macam ilmu agama Islam.

Dalam membaca Al Qur'an tentunya tidak boleh asal baca dan harus hati-hati. karena tidak boleh salah cara pengucapan makhrojnya dan tajwidnya karena akan mempengaruhi arti dari $\mathrm{Al}$ Qur'an itu. Untuk itu di perlukan metode

${ }^{1}$ Abdul Djalal, Ulumul Qur'an, (Surabaya: Dunia Ilmu, 2008), h. 9.

2 Rif'at Syauqi Nawawi, Kepribadian

Qur"ani, (Jakarta: Amzah, 2014), h. 240. yang cocok agar peserta didik bisa membaca Al-Qur'an dengan baik dan benar sesuai dengan hukum bacaannya. ${ }^{3}$

Salah satu upaya yang di lakukan oleh MTs Negeri 1 Kota Kediri dalam membekali para siswanya untuk menjadi penerus bangsa yang senantiasa berpegang teguh dengan ajaran Islam yakni dengan adanya pembelajaran bimbingan baca tulis Al Qur'an (BBTQ). Yang di ajarkan pada hari Senen Selasa Rabu kamis dengan mengambil guru pengajar dari madrasah Murottil Qur'an Lirboyo, sedangkan untuk tingkatan pembelajaran BBTQ di MTs Negeri 1 Kota Kediri di bagi dua tingkatan yang pertama tingkatan jet tempur dan tingkatan persiapan membaca Al Qur'an. Tingkatatan jet tempur adalah tingkatan pemulan untuk mengenal huruf A BA TA, untuk fokus penelitian ini di kususkan tingkatan jet tempur, gunana untuk mengetahu metode jet tempur dan untuk mengetahui hasil pembelajaran BBTQ dengan metode jet tempur. Kedua tingkatan persiapan tingkatan persiapan yaitu para persertanya sudah bisa mengenal hurur hijah iya tinggal membenarkan bacaanya saja atau agar mengenal hukum hukum bacaan $\mathrm{Al}$ Qur'an. Dalam membagai dua tingaktan tersebut di adakan tes terlebih dahulu, yang mencakup satu tes lisan kedua tes tulisan, yang di ikuti oleh semu siswa

${ }^{3}$ M, Fathul lilah, Masa,il Al-Qur'an (Kediri: Santri Salaf Pres, 2017),h. 24. 
kelas VII. Di adakan tes tersebut bisa mengetahu kemampua siswa, dan untuk meyesuaikan tingkatan siswa biar nantinya pengajar bisa mudah menerapakan metode yang tepat sesuai dengan kemampuan siswa tersebut. Sedangakan metode jet tempur untuk saat ini sangat efektif sekali yang dulu siswa tida mengal hurur ijaiah sekarang sudah bisa dan sudah tahu bacaan panjang pendeknya bacaan sesuai hukum bacaan. ${ }^{4}$

Di karenakan membaca Al Qur'an dengam tajwid itu hukumnya fardu 'ain dan berdasarkan beberapa nash atau dalil Al Qur'an Al Hadits dan ijma 'ul ummah atau mufakatnya para Ulama, seperti firmanya Allah:

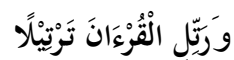

Terjemahnya: "Dan bacalah Al-Quan dengan perlahan lahan yang jelas," (QS. Muzammil, ayat 4). ${ }^{5}$

Firman Allah tersebut di kuatkan dengan sabdanya "TARTILAN' artinya dengan tartil dan sesungguhnya. supaya betul-betul diperhatikan olehnya memeperbaiki bacaan Al Qur'an. ${ }^{6}$

Keberhasilan suatu program, terutama pengajaran dalam proses belajar mengajar tidak terlepas dari pemilihan metode. Di negara indonesia terdapat banyak metode pembelajaran Al-Qur'an

\footnotetext{
${ }^{4}$ Wawancara, Zainui Nadip, Rosunnawa, 16 Januari 2019.

5 Al-Qur'an,4:

6 Maftuh Basthul Birri, Standar Tajwid Bacaan Al-Quran, terj . Maftuh Basthul Birri (P.P,. Lirboyo Kediri:Madrasah Murottilil Quranil Karim,2018),h.23.
}

7 Akmal Mundiri \& Irma Zahra," Implementasi Metode Stifin Dalam Meningkatkan yang digunakan. tujuan metode tersebut untuk meningkatkan kemampuan belajar anak. Akan tetapi metode yang digunakan tidak selalu cocok untuk peserta didik karena kadang-kadang metode yang digunakan tidak sesuai dengan keadaan peserta didik.

Menurut Novan Ardi, metode dalam Bahasa Arab dikenal dengan istilah thariqah yang berarti langkahlangkah yang diambil seorang pendidik guna membantu peserta didik merealisasikan tujuan tertentu. ${ }^{7}$ Metode jet tempur adalah salah satu metode membaca Al Qur"an yang lebih ditekankan pada hafalan. Dengan menggunakan buku jer tempur yang buku tersebut pas sekali di gunakn untuk kalangan pemulan belajar Al Qur'an. ${ }^{8}$

Menurut Zuhairini dan Ghofir sebagaimana yang dikutip oleh Ridwal Kamil dalam bukunya yang berjudul "Mengapa Kita Menghafal (Tahfizh) Al Qur'an", istilah menghafal adalah suatu metode yang digunakan untuk mengingat kembali sesuatu yang pernah dibaca secara benar seperti apa adanya. Metode tersebut banyak digunakan dalam usaha untuk menghafal Al Qur'an dan Al-Hadist. Jadi menghafal adalah berusaha meresapkan ke dalam fikiran agar bisa selalu diingat tentang sesuatu yang dibaca. ${ }^{9}$

Kemampuan Menghafal Al-Qur'an Di Rumah Qur'an Stifin Paiton Probolinggo", Jurnal Pendidikan Agama Islam, Volume 5 No 2 (2017), h. 204

${ }^{8}$ Birri, h.68.

9 Mafrudah," Peningkatan Kemampuan Hafalan Materi Al-Quran Hadis melalui Metode Index Card Match pada Siswa Kelas VIII-F MTs 
Menurut Mohamad Surya guru profesional adalah guru yang mempuyai keahlian, tanggung jawab, dan rasa kesejawatan yang di dukung oleh etika profesi yang kuat. Untuk itu iya harus memiliki kualifikasi kopetensi yang memadahi, kopentensi intelektual, sosial, spiritual, peribadi dan moral. ${ }^{10}$ Sedangkan menurut Rauf, A. definisi menghafal adalah: "proses mengulang sesuatu baik dengan membaca atau mendengar, pekerjaan apapun jika sering diulang, pasti menjadi hafal."

Berdasarkan pengertian di atas, maka dapat disimpulkan bahwa menghafal $\mathrm{Al}$ Qur'an berarti mengingat-ingat bacaan Al Qur'an dan dilakukan secara berulangulang baik dengan mendengar maupun dengan membacanya. ${ }^{11}$

Baca tulis Al Qur'an merupakan kegiatan seseorang dalam melisankan serta melambangkan huruf huruf $\mathrm{Al}$ Qur'an. Sementara kopetensi baca tulis al qur'an merupakan kesanggupan seseorang dalam melisankan dan membunyikan serta melambangkan huruf huruf Al Qur'an.

Berdasarkan kajian tersebut, peneliti merasa tertarik untuk meneliti kepraktisan dan efektifitas penggunaan metode jet tempur di MTs Negeri 1 Kota Kediri tepatnya di Jl.Raung No.87, Bandar Kidul, Mojoroto, Jaw Timur, dengan judul implementasi metode jet tempur dalam meningkatkan Bimbingan

Negeri I Bantul", Jurnal Pendidikan Madrasah, Volume 3, No 1, (Mei 2018), h, 30.
Baca Tulis Al-Quran di MTs Negeri 1 Kota Kediri

\section{Metode}

Pendekatan penelitian yang digunakan dalam penelitian ini adalah pendekatan kualitatif-diskriptif (qualitative-diskription). Bogdan dan Taylor mendefinisikan metodologi kualitatif sebagai prosedur penelitian yang menghasilkan data deskriptif berupa kata-kata tertulis atau lisan dari orangorang dan perilaku yang dapat diamati.

Pendekatan ini diarahkan pada latar dari individu tersebut secara holistik (utuh). Jadi dalam hal ini tidak boleh mengisolasikan individu atau organisasi ke dalam variabel atau hipotesis, tapi perlu memandangnya sebagai bagian dari suatu keutuhan. Analisis data kualitatif bersifat induktif, yaitu analisis berdasarkan data yang diperoleh. Menurut Miles \& Huberman analisis terdiri dari tiga alur kegiatan yang terjadi secara bersamaan yaitu: reduksi data, penyajian data, penarikan kesimpulan/ verifikasi.

\section{Hasil dan Pembahasan}

\section{Metode Jet Tempur}

Metode pembelajaran jet tempur memiliki keunikan sendiri dibandingkan dengan metode pembelajaran klasik seperti yang terdapat di TPA. Metode pembelajran jet tempur ini lebih mengedepankan proses dengan

11 Cucu Susianti," Efektivitas Metode Talaqqi Dalam Meningkatkan Kemampuan Menghafal Al-Qur'an Anak Usia Dini", Jurnal Pendidikan, Vol.2, No.1, (April 2016), h. 9. 
berprinsip pembelajaran bukan hanya hafalan semata. Metode Jet Tempur dimulai dengan mengenalkan huruf hijayyah asli tanpa harokat dan pelafalannya. Misalnya alif, ba', ta', tsa',jim. Sedangkan model klasik dimulai dengan pengenalan huruf hijayyah dan pelafalannya yang sudah diberi harokat misalnya a, ba, ta, tsa, ja. Cara melafalkan hurufnya juga tidak langsung a, ba, ta tapi disertai proses yang terjadi misalnya "hamzah alif fattah a". Metode pembelajaran memiliki cara unik untuk melatih santrinya berpikir kritis yaitu dengan cara tidak akan membenarkan bacaan yang salah sampai anak menemukan kesalahannya sendiri. Karena itu metode ini membutuhkan waktu yang lebih lama dalam pembelajaran membaca Al Qur'an.

Metode jet tempur juga menggunakan sistem semester ganjil dan genap dan tidak seperti TPA pada umumnya yang hanya memberikan kartu prestasi di jet tempur masing-masing santrinya diberikan laporan hasil belajar per semester berupa penilaian kognitif dan sikap layaknya sekolah formal. Terdapat 6 kelas dalam Jet tempur, kelas awal dimalai dengan kelas SP (sekolah persiapan) kemudian dilanjutkan dengan kelas 1,2,3,4,5,6. Mata pelajaran Jet Tempur meliputi Tajwid ( ilmu tentang membaca Al-Qur'an), Tauhid (ilmu tentang keesaan tuhan), Fiqih, ilmu akhlak, imla' (cara melafalkan bacaan AlQur'an), Qiro'atul Qur'an, Muhafadzoh, dan fasholatan.
Pembelajaran jet tempur memiliki beberapa tata tertib yang unik. Adapun tata tertib nya adalah:

a. Disiplin dalam mengikuti kegiatan selama satu minggu dan izin bila tidak masuk

b. Memakai baju muslim dan tidak menggunakan lengan pendek dan celana $3 / 4$ (sebatas betis)

c. Berlaku jujur dan dapat dipercaya

d. Melaksanakan sholat 5 waktu

e. Membersihkan tempat belajar sesuai jadwal yang ada

f. Tidak mengeluarkan kata kotor (mengumpat)

g. Menjaga nama baik Tarbiyatul Qur'an

Hasil Pembelajaran Bimbingan Baca Tulis Al Qur'an (BBTQ) Dengan Menggunakan Metode Jet Tempur Di MTs Negeri 1 Kota Kediri

Untuk membutikan pencapaian hasil dari pembelajaran menggunkan metode jet tempur yang di lakukan oleh ustadaz jet tempur di MTs Negeri 1 Kota Kediri yaitu dengan dengan beberapa setrategi yang pertama:

a. Tes formatif untuk mengetahui tercapai tidaknya pembelajaran bimbingan baca Tulis Al-Qur'an (BBTQ), ustadaz jet tempur di MTs Negeri 1 Kota Kediri dengan menggunkan metode di atas ustadaz mengadakan tes formatif pada setiap menyajikan suatu bahasan pada peserta didik. Penilaian formatif ini untuk mengetahui sejauh mana peserta didik telah menguasai tujuan pembelajaran yang ingin dicapainya. 
Hal ini juga ditegaskan oleh Arikunto ,bahwa "tes formatif harus dilaksanakan oleh guru setiap mengakhiri satu subpokok bahasan, sedangkan tes sumatif dilaksanakan setiap mengakhiri satu pokok bahasan" 12

Dengan hal itu apa yang di lakukan oleh ustadaz di MTs Neggeri 1 Kota Kediri dengan melaksanakan tes formatif pada setiap meyajikan satu pembahasn terbukti sangat ampuh sekali, sehingga ustadaz bisa mengetahui kekurangan siswanya dan jadikan bahan evaluasi setiap harinya.

b. Evaluasi dengan adanya evaluasi yang di lakukan oleh ustadat jet tempur di MTs Neggeri 1 Kota Kediri pada peserta didik pada tiap minngunya dan pada akhir semester dengan ujian lisan dan ujian tulis terbukti dapat mengetahui sejauh mana keberhasilan yang telah dicapai selarna mengikuti pendidikan.

Pertama, siswa sudah dapat memperatekan ilmu tajwid saat membca Al Qur'an dengan nilai baik. Kedua, siswa sudah mengenali huruf ijiyah dengan nilai baik. Ketiga siswa sudah menghafal surat pendek dengan nilai baik. Dan dengan dilihat nilai pada ujian akhir semester dengan pendapatan nilai rata rata siswa mendapatkan nilai sepuluh.
Sedangkan evaluasi pembelajaran jet tempur dengan menngunankan metode jet tempur, metode derill , metode ceramah, metode demonstrasi, adalah berpusat sejahu manah siswa paham ilmu tajwid dan penerapan ilmu tajwid setiap suswa membaca Al Qur'an setiap harinya dan juga sejauh manah kepandaian siswa menulis al quran dengan kaidah tulisan ustmani.

Pendapat tersebut di kuatkan oleh Jalaludin yang mengatakan bahwa evaluasi dalam pendidikan lslam telah menggariskan tolak ukur yang serasi dengan tujuan pendidikannya. Baik tujuan jangka pendek yaitu membimbing manusia agar hidup selamat di dunia, maupun tujuan jangka panjang untuk kesejahteraan di akhirat nanti. Kedua tujuan tersebut menyatu dalam sikap dan tingkah laku yang mencerminkan akhlak yang mulia. Sebagai tolak ukur dan akhlak mulia ini dapat dilihat dari cerminan tingkah laku dalam kehidupan sehari-hari.13

Untuk mengetahui perkembangan hasil yang telah dicapai oleh peserta didik dalam belajar, maka harus adanya kegiatan evaluasi. Evaluasi yang di lakukan ustadaz di MTs Neggri 1 Kota Kediri ada kriteria (patokan) seperti penilaian kelancaran dan penilaian tajwid yang mengacu
12 Mochammad Khafid," Pengaruh Pemberian Tes Formatif Terhadap Peningkatan

Hasil BelajarPendidikan Kesehatan Pada Siswa Kelas Vii Smp Negeri 2 Krian", Jurnal Pendidikan
Olahraga dan Kesehatan ,Vol. 2 ,No, 01 (Tahun 2014), h.121.

${ }^{13}$ Mahirah B, "Evaluasi Belajar Peserta Didik (Siswa)", Jurnal Pendidikan, Vol. I, No. 2, (Desember 2017), h. 259. 
pada tujuan yang telah ditentukan sehingga dapat diketahui seberapa besar pengaruh strategi belajar mengajar terhadap keberhasilan belajar siswa.

c. Tujuan, fungsi, dan manfaat evaluasi tujuan Evaluasi Evaluasi adalah suatu kegiatan yang disengaja dan bertujuan. Kegiatan evaluasi dilakukan dengan sadar oleh guru dengan tujuan untuk memperoleh kepastian mengenai keberhasilan belajar siswa dan memberikan masukan kepada guru mengenai apa yang dia lakukan dalam kegiatan pengajaran. Dengan kata lain, evaluasi yang dilakukan oleh guru bertujuan untuk mengetahui bahan bahan pelajaran yang disampaikan apakah sudah dikuasi oleh siswa ataukah belum. Selain itu, apakah kegiatan pegajaran yang dilaksanakannya itu sudah sesuai dengan apa yang diharapkan atau belum.

Menurut Sudirman N, dkk, bahwa tujuan penilaian dalam proses pembelajaran adalah:

1. Mengambil keputusan tentang hasil belajar.

2. Memahami siswa,

3. Memperbaiki dan mengembangkan program pengajaran. Selanjutnya, mengatakan bahwa pengambilan keputusan tentang hasil belajar merupakan suatu keharusan bagi seorang guru agar dapat mengetahui berhasil tidaknya siswa dalam proses pembelajaran. d. Ketidakberhasilan proses pembelajaran itu disebabkan antara lain sebagai berikut:

1. Kemampuan siswa yang rendah.

2. Kualitas materi pelajaran tidak sesuai dengan tingkat usia anak.

3. Jumlah bahan pelajaran terlalu banyak sehingga tidak sesuai dengan waktu yang diberikan.

4. Komponen proses belajar dan mengajar yang kurang sesuai dengan tujuan yang telah ditetapkan oleh guru itu sendiri.

Di samping itu, pengambilan keputusan juga sangat diperlukan untuk memahami siswa dan mengetahui sampai sejauh mana dapat memberikan bantuan terhadap kekurangan siswa. Evaluasi juga bermaksud meperbaiki dan mengembangkan program pengajaran. Dengan demikian, tujuan evaluasi adalah untuk memperbaiki cara, pembelajaran, mengadakan perbaikan dan pengayaan bagi siswa, serta menempatkan siswa pada situasi pembelajaran yang lebih tepat sesuai dengan tingkat kemampuan yang dimilikinya. Tujuan lainnya adalah untuk memperbaiki dan mendalami dan memperluas pelajaran, dan yang terakhir adalah untuk memberitahukan atau melaporkan kepada para orang tua/wali siswa mengenai penentuan kenaikan kelas atau penentuan kelulusan siswa.

e. Fungsi Evaluasi. Evaluasi yang sudah menjadi pokok dalam proses keberlangsungan, pendidikan maka sebaiknya dikerjakan setiap hari seperti ustadaz jet tempr lakukan di MTs Neggeri 1 Kota Kediri dengan jadwal yang sistematis dan terencana. 
Guru dapat melakukan evaluasi tersebut dengan menempatkannya secara satu kesatuan yang saling berkaitan dengan mengimplementasikannya pada satuan materi pembelajaran. Bagian penting lainnya yaitu bahwa guru perlu melibatkan siswa dalam evaluasi sehingga secara sadar dapat mengenali perkembangan pencapaian hasil belajar pembelajaran mereka, Sehingga salah satu komponen dalam pelaksanaan pendidikan. Evaluasi mempunyai beberapa fungsi

Menurut Sukardi, evaluasi memiliki beberapa jenis yaitu: (1) evaluasi harus masuk dalam kisikisi yang telah ditentukan; (2) evaluasi sebaiknya dilaksanakan secara komprehensip; (3) evaluasi diselenggarakan dalam proses kontinu; dan (4) evaluasi harus mempertimbangkan nilai-nilai yang berlaku $^{14}$

Sesuai dengan permasalahan evaluasi yang dikemukakan di atas, maka peneliti menemukan pelaksanan evaluasi di MTs Neggeri 1 Kota Kediri sesuai dengan teori teori yang ada sehinga pembelajaran jet tempur di MTs Neggeri 1 Kota Kediri dapat di ketahu hasilnya dengan baik.

\section{Kesimpulan}

Dari hasil penelitian penulis di MTs Negeri 1 Kota Kediri mengenai pembelajaran menggunakan metode jet tempur di MTs Negeri 1 Kota Kediri dapat di ambil kesimpulan sebagai berikut:

1. Strategi dalam meningkatkan kemampuan membaca Al Qur'an melalui metode Jet Tempur di MTs Negri 1 Kota Kediri yaitu:

a. Melalui pendekatan dengan siswa dan pendekatan yang berpusat pada guru.

b. Dengan menggunakan metode pendukung seprti metode ceramah, metode tanya jawab, dan metode demonstrasi sesuai dengan metode jet tempur yaitu menghafal setiap suarat pendek.

c. Dengan adanya bemberian contoh yang di sampekan ustadz melalu murotalan

d. Dengan di adakan evaluasi dengan memperaktekan bacaan satu persatu pada siswa

2. Hasil pembelajaran bimbingan baca tulis al-qur'an (BBTQ) dengan menggunakan metode jet tempur di Mts Neggeri 1 Kota Kediri

Hasil belajar dari pembelajaran Baca Tulis Al Qur'an dapat dikatakan cukup berhasil, karena sebelumnya banyak yang belum bisa membaca $\mathrm{Al}$ Qur'an, bahkan belum mengenal huruf hijaiyah tapi sekarang sudah meningkat dan bisa membaca Al Qur'an.

Muhammadiyah Palangkaraya ", Anterior Jurnal, Vol. 13, No 1, (Desember, 2013), h. 89. 


\section{Daftar Pustaka}

Birri, Maftuh Basthul, Standar Tajwid Bacaan Al-Quran, terj. Maftuh Basthul Birri Kediri: Madrasah Murottilil Quranil Karim, 2018

Djalal, Abdul, Ulumul Qur'an, Surabaya: Dunia Ilmu, 2008

Fathullilah, M., Masa,il Al-Qur'an Kediri: Santri Salaf Pres, 2017

Hendri, Edi, "Guru Berkualitas Profesional Dan Cerdas Emosi", Jurnal Saung Guru, vol. 1 no .2.(2010)

Khafid, Mochammad,"Pengaruh Pemberian Tes Formatif Terhadap Peningkatan Hasil BelajarPendidikan Kesehatan Pada Siswa Kelas Vii Smp Negeri 2 Krian", Jurnal Pendidikan Olahraga dan Kesehatan ,Vol. 2 ,No, 01 (Tahun 2014)

Mafrudah," Peningkatan Kemampuan Hafalan Materi Al-Quran Hadis melalui Metode Index Card Match pada Siswa Kelas VIII-F MTs Negeri I Bantul", Jurnal Pendidikan Madrasah, Volume 3, No 1, (Mei 2018)

Mahirah B, "Evaluasi Belajar Peserta Didik (Siswa)", Jurnal Pendidikan, Vol. I, No. 2, (Desember 2017)

Mundiri, Akmal \& Zahra, Irma "Implementasi Metode Stifin Dalam Meningkatkan Kemampuan Menghafal Al-Qur'an Di Rumah Qur'an Stifin Paiton Probolinggo", Jurnal Pendidikan Agama Islam, Volume 5 No 2 (2017)

Nawawi, Rif'at Syauqi, Kepribadian Qur "ani, Jakarta: Amzah, 2014
Nurbudiyani, Iin, "Pelaksanaan Pengukuran Ranah Kognitif, Afektif, Dan Psikomotor Pada Mata Pelajaran Ips Kelas Iii Sd Muhammadiyah Palangkaraya ", Anterior Jurnal, Vol. 13, No 1, (Desember, 2013)

Susianti, Cucu, "Efektivitas Metode Talaqqi Dalam Meningkatkan Kemampuan Menghafal Al-Qur'an Anak Usia Dini", Jurnal Pendidikan, Vol.2, No.1, (April 2016) 
Implementasi Metode Jet Tempur Dalam Meningkatkan

Bimbingan Baca Tulis Al Qur'an Di MTs Negeri 1 Kota Kediri

Oleh: Mu'min Ali Murtado \& Miftahudin 